\title{
Cow-Calf Producer Perceptions Regarding Individual Animal Traceability
}

\author{
Lee L. Schulz and Glynn T. Tonsor
}

\begin{abstract}
This study provides valuable insights into cow-calf producer voluntary participation in the National Animal Identification System and producers' perceptions of several issues critically impacting the success of voluntary traceability systems. Cow-calf producers believe that the most important issues to the U.S. beef industry in designing a national, individual animal traceability system are monitoring/managing disease, maintaining current foreign markets, accessing foreign markets, and increasing consumer confidence. Furthermore, producers are concerned with cost, liability, reliability of technology, failure of system to meet stated goals, and confidentiality of information associated with these systems.
\end{abstract}

Key Words: animal traceability, cow-calf, National Animal Identification System, voluntary adoption

JEL Classifications: Q12, Q18, R38

Individual animal traceability allows producers to identify individual animals, the premises where they were located, and their movements throughout the supply chain. According to Saatkamp et al. $(1995,1997)$, the type of individual animal traceability system that an industry has in place can significantly impact the duration, spread, and economic consequences of a foreign animal disease. There are several benefits of individual animal traceability adoption to industry stakeholders, government health professionals, food safety regulators, and consumers. Namely, Schroeder et al. (2009) identify these as enhanced animal health surveillance and improving consumer demand because of the presence of food product credence attributes associated with food

Lee L. Schulz is graduate research assistant and Glynn T. Tonsor is assistant professor, Department of Agricultural Economics, Kansas State University, Manhattan, KS.

We acknowledge, without implication, BEEF Magazine for providing the mailing list for our survey and three anonymous reviewers and the editors for comments on earlier versions of this article. and animal traceability. Overall, animal identification and traceability provides a direct link to where an animal originated and provides an efficient way to identify sources of and quickly solve animal production problems that affect overall value of animals throughout production and processing (Schroeder et al., 2009).

With traceability becoming ever more important within the beef industry for verification of animal health as well as marketing purposes, the need for traceability systems that are attractive to producers as well as meet the goals that they were designed for is evident. Because cow-calf producers are the first player in the beef supply chain and vary widely in scale and production practices of their operations, it is crucial to consider the demographics, production practices, and perceptions of cow-calf producers when attempting to implement industrywide systems. This is especially important when attempting to implement individual animal traceability and maximize participation rates of these systems because the views of these producers will most certainly impact the success or failure of these efforts. 
Bulut and Lawrence (2007, pp. 1, 5) state, "there is not a commonly accepted and one-type fits-all definition for traceability and that, particularly, a two-part-system has developed in the beef and cattle industry; meat traceability and live animal traceability." Becker (2007, p. 2) defines an extensive form of meat traceability as "the ability to follow products forward from their source animal (i.e., birth or ancestry), through growth and feeding, slaughter, processing, and distribution, to the point of sale or consumption (or backward from the consumer to the source animal)." In this article, we focus on live animal traceability, leaving meat traceability issues for future research.

Live animal traceability can be accomplished through a variety of systems. The main function of live animal traceability systems is to quickly identify agricultural premises exposed to an animal disease so that the disease can be more effectively controlled or eradicated. Furthermore, live animal traceability has the potential to provide proactive information and quality verification, which is essentially an increase in production information available to entities throughout the supply chain.

Because there is not a one-type-fits-all definition for traceability, responsibility and design typically falls on the parties such as the U.S. Department of Agriculture (USDA), defining the objectives, implementing, and overseeing the traceability systems. According to SouzaMonteiro and Caswell (2004, p. 3), "economic and technical decisions on which type of traceability system should be designed and implemented involve trade-offs between system features and their related benefits and costs." Economics of traceability systems involves describing the economic incentives motivating traceability systems. "The economic incentives pushing these new systems originate from the forces changing the meat marketplace and include improving animal health management and rapid response systems, meeting consumer demands for meat safety, maintaining and building international trade, verifying product credence attributes, properly assigning liability, and in improving management throughout the meat supply chain" (Tonsor and Schroeder, 2006, p. 107).
Golan et al. (2004) report the existence of several beef traceability systems in the U.S. Most of these traceability systems have been private and market-driven, although there have been some state and nationwide initiatives to implement individual animal traceability. Private sector traceability includes individual supply chain initiatives and industrywide programs.

The National Animal Identification System (NAIS) is the national livestock traceability system in the U.S. that evolved from previous efforts to implement a national voluntary livestock traceability system. According to Murphy, Pendell, and Smith (2009), "NAIS was originally designed as a mandatory program, but due to strong opposition, the USDA changed directions and published a revised 'User Guide' in November 2006, which stated that NAIS would become a voluntary program at the federal level" (U.S. Department of Agriculture-Animal and Plant Health Inspection Services [USDAAPHIS], 2007) (p. 3). The NAIS is the most comprehensive effort ever launched in the U.S. livestock industry to enhance the ability to quickly identify and contact animal premises, promote animal identification, and develop animal movement and tracing capabilities (Schroeder et al., 2009). ${ }^{1}$ This national traceability system consists of three components: premise registration, animal identification, and animal tracing (USDA-APHIS, 2008b). Premise registration is the foundation of NAIS and allows owners of premises to voluntarily register their premises with their state or tribal animal health authority. Animal identification provides producers with a uniform numbering system for their animals. Animal tracing still requires the most development by individual states and the private sector. Currently, producers do have access to several animal tracking databases for reporting the movement of animals throughout the supply chain. State and private industry animal tracking databases hold the animal location and movement records that producers report.

${ }^{1}$ NAIS covers a broad array of animal species. USDA-APHIS (2008a) designates bovine as highest priority for NAIS development; medium priority for porcine, equine, poultry, cervid, and caprine; and low priority for ovine and aquatics. 
The focus of NAIS is on animals that enter commerce, moving from their farm to markets or locations where they comingle with other animals (Cattle Network, 2008). Producers who choose to participate in NAIS become part of a national animal disease response network, which provides a streamlined system of information (USDA-APHIS, 2007). For traceability systems to be most effective and provide a full traceable history of animal movements, adoption is needed at the cow-calf sector. Schroeder et al. (2009) found that the greatest need and the greatest challenge for (NAIS) adoption is in the animal breeding herd.

\section{Work Needed}

There has been little research on beef industry perceptions regarding voluntary traceability. Research in this area is especially important when attempting to implement individual animal traceability and maximize participation rates of these systems because the views of these producers will most certainly impact the success or failure of these efforts. A few recent economic studies have addressed beef industry perceptions regarding traceability. Buhr (2003) focused on the economics of information systems by investigating six European organizations, two of which involved the beef supply chain, using traceability programs. ${ }^{2}$ Participants of this study "report that traceability often has internal production benefits from improved information and control of production even though traceability has generally been couched as a supply chain management issue driven by consumer demand" (Buhr, 2003, p. 17).

Bailey and Slade (2004) conducted a survey to measure the level of support among state veterinarians and representatives of producer groups. They examined the support for the U.S.

${ }^{2}$ The two participating entities from the beef supply chain were Scase-Intentia/Gilde, a lamb, pork, and beef supply chain in Norway; and Scotbeef, a beef production system in Scotland. The traceability systems used by these entities extended from the feed manufacturing process through retail (Buhr, 2003).
Animal Identification Plan (USAIP) based on producers' concerns about animal health and the perceived costs and benefits accrued to different levels of the marketing chain. The study found that over $90 \%$ of state cattle producer association respondents indicated support for a national cattle identification program, whereas only $41 \%$ indicated that they supported the USAIP (Bailey and Slade, 2004). Bailey and Slade (2004, p. 17) conclude that "the reason for this disagreement exists because veterinarians see the role of USAIP as being principally related to maintaining animal and human health while producer associations are also worried about the market implications related to the implementation of the USAIP." The results of this study provide evidence showing that producers do support traceability, but also points out the need for more clearly identifying producers' expectations and concerns regarding traceability.

A majority of the past research has sought to analyze consumers' perceptions toward voluntary traceability (Dickinson and Bailey, 2002; Dickinson, Hobbs, and Bailey, 2003). However, as previously noted, there has been little research on producers' perceptions concerning voluntary traceability. Given that beef traceability is voluntary for producers, producer perceptions are nearly the sole driver of adoption. Models in this study examine cow-calf producers' perceptions regarding voluntary traceability. Specific examples include: examinations of self-revelation of current NAIS participation and the most current concerns and important issues to cow-calf producers regarding traceability.

This study provides valuable insights into cow-calf producer perceptions of several issues critically impacting the success of the voluntary NAIS program. The first objective was to determine what type of producers have premises currently registered in NAIS. Knowledge of these characteristics will help governing entities such as the USDA better serve current NAIS participants as well as identify the characteristics of producers not currently participating and thus enabling more efficient resource allocation in efforts to expand current systems and participation.

When designing a national, individual animal traceability system, the identity or functions 
served by the system are critical. The second objective was to examine what producers felt was the most important functions a traceability system should serve. These issues help identify the system such as for disease management and/or marketing. Giving a clear identity to a proposed traceability system will assist in promoting the system to producers and the public and should help increase participation rate.

Previous studies identified cost to producer, reliability of technology, confidentiality of information, and liability to the producer as top concerns of cow-calf producers regarding traceability (Breiner, 2007). Given this previous research, an objective of this study was to determine if these concerns as well as additional concerns and issues were still of top apprehension to participation or have producers' perceptions shifted within the industry.

A great deal of controversy has developed in response to the country of origin labeling (COOL) law and guidelines. The enactment of COOL in September 2008 required retailers to label fresh beef, pork, lamb, chicken, and goat as well as other products according to its country of origin. ${ }^{3}$ All retailers and suppliers are required to maintain origin information for 1 year for covered products that they sell, whereas producers must maintain records that can link animals sold to production records documenting animal origin. If animal sorting and comingling from multiple sources occurs, the burden of maintaining origin records could be reduced with individual animal traceability (Schroeder et al., 2009). There has been an argument in the cattle industry that individual animal traceability is unnecessary if COOL were implemented nationally. A final objective was to identify the characteristics of the cow-calf producers that agree with this argument. This will help the USDA better identify these producers when they are attempting to increase participation

3 "The Farm Security and Rural Investment Act of 2002 (2002 Farm Bill), the 2002 Supplemental Appropriations Act (2002 Appropriations), and the Food, Conservation and Energy Act of 2008 (2008 Farm Bill) amended the Agricultural Marketing Act of 1946 (Act) to require retailers to notify their customers of the country of origin of covered commodities" (USDA-AMS, 2009, p. 2658). in NAIS, because there is a need to educate producers of the benefits of the coexistence of COOL and individual animal traceability. Combined, this study provides the first comprehensive analysis of cow-calf producer participation in NAIS and perceptions of traceability that are critically valuable to the USDA in future management of NAIS and related programs.

\section{Data}

A mail survey was designed to obtain information from U.S. cow-calf producers regarding demographics, production practices, and beliefs regarding individual animal traceability. On November 26, 2007, a total of 2000 (1998 effective) surveys were mailed to cow-calf producers (selected on a random "nth" name basis by BEEF Magazine) throughout the United States. A $\$ 1$ bill was included in the survey to potentially increase participation and response (Gregory, 2008). Postcards reminding producers to complete the survey were sent 2 weeks after the initial mailing with an Internet link to a survey being made available on the postcard. The random selection of producers to receive the survey allowed equal opportunity for selection regardless of participation in various farm organizations; however, given that BEEF Magazine subscribers traditionally have herd sizes greater than 100 animals, the sample was not expected to be completely representative of the diverse population of U.S. cow-calf operations. The respondent pool provided 609 useable surveys (30.48\% effective response rate). ${ }^{4}$ As described subsequently, sample weights were constructed to force the sample to match the U.S. cattle operation numbers in terms of beef cows that calved in 2007.

The comprehensive survey included questions regarding various aspects of cow-calf production, including demographics, current production practices, and perceptions concerning traceability. Table 1 reports the variable names, definitions, sample means, and standard deviations for the variables used in the econometric models.

\footnotetext{
${ }^{4}$ Michigan respondents (five) were not included in the final data set because of the mandatory nature of the state's individual, beef traceability system.
} 
Table 1. Summary Statistics on Select Sample Characteristics

\begin{tabular}{|c|c|c|c|}
\hline $\begin{array}{l}\text { Variable/ } \\
\text { Question }\end{array}$ & Description & $\begin{array}{l}\text { Unweighted } \\
\text { Mean }^{\mathrm{a}}\end{array}$ & $\begin{array}{l}\text { Weighted } \\
\text { Mean }^{\mathrm{b}}\end{array}$ \\
\hline \multirow[t]{7}{*}{ YRSR } & $\begin{array}{l}\text { Years raising beef cattle } \\
=1 \text { if less than } 5 \text { years }\end{array}$ & $\begin{array}{c}0.010 \\
(0.099)\end{array}$ & $\begin{array}{c}0.043 \\
(0.204)\end{array}$ \\
\hline & $=2$ if $6-10$ years & $\begin{array}{c}0.033 \\
(0.179)\end{array}$ & $\begin{array}{c}0.071 \\
(0.257)\end{array}$ \\
\hline & $=3$ if $11-15$ years & $\begin{array}{c}0.046 \\
(0.210)\end{array}$ & $\begin{array}{c}0.034 \\
(0.181)\end{array}$ \\
\hline & $=4$ if $16-20$ years & $\begin{array}{c}0.049 \\
(0.217)\end{array}$ & $\begin{array}{l}0.075 \\
(0.263)\end{array}$ \\
\hline & $=5$ if $21-25$ years & $\begin{array}{c}0.086 \\
(0.280)\end{array}$ & $\begin{array}{c}0.104 \\
(0.305)\end{array}$ \\
\hline & $=6$ if $26-30$ years & $\begin{array}{c}0.102 \\
(0.303)\end{array}$ & $\begin{array}{c}0.088 \\
(0.283)\end{array}$ \\
\hline & $=7$ if over 30 years & $\begin{array}{c}0.672 \\
(0.470)\end{array}$ & $\begin{array}{c}0.584 \\
(0.493)\end{array}$ \\
\hline \multirow[t]{8}{*}{ EXPYRS } & Expected years raising beef cattle & & \\
\hline & $=1$ if less than 5 years & $\begin{array}{c}0.118 \\
(0.323)\end{array}$ & $\begin{array}{c}0.218 \\
(0.413)\end{array}$ \\
\hline & $=2$ if $6-10$ years & $\begin{array}{c}0.167 \\
(0.374)\end{array}$ & $\begin{array}{l}0.215 \\
(0.411)\end{array}$ \\
\hline & $=3$ if $11-15$ years & $\begin{array}{c}0.116 \\
(0.321)\end{array}$ & $\begin{array}{c}0.071 \\
(0.256)\end{array}$ \\
\hline & $=4$ if $16-20$ years & $\begin{array}{c}0.148 \\
(0.355)\end{array}$ & $\begin{array}{c}0.053 \\
(0.224)\end{array}$ \\
\hline & $=5$ if $21-25$ years & $\begin{array}{c}0.075 \\
(0.263)\end{array}$ & $\begin{array}{c}0.102 \\
(0.303)\end{array}$ \\
\hline & $=6$ if $26-30$ years & $\begin{array}{c}0.035 \\
(0.183)\end{array}$ & $\begin{array}{r}0.089 \\
(0.285)\end{array}$ \\
\hline & $=7$ if over 30 years & $\begin{array}{c}0.342 \\
(0.475)\end{array}$ & $\begin{array}{c}0.252 \\
(0.434)\end{array}$ \\
\hline
\end{tabular}

NCBA Are you a member of the National Cattlemen's Beef Association (NCBA)?

$=1$ if yes; 0 otherwise

$\begin{array}{cc}0.222 & 0.149 \\ (0.416) & (0.356)\end{array}$

RCALF Are you a member of the Ranchers and Cattlemen's

Action Legal Fund (RCALF)?

$=1$ if yes; 0 otherwise

$\begin{array}{cc}0.130 & 0.024 \\ (0.336) & (0.153)\end{array}$

COLLEGE Did you receive a bachelor's, graduate, or professional degree?

$$
\begin{aligned}
& =1 \text { if yes; } 0 \text { otherwise } \\
& =1 \text { if less than } \$ 25,000 \\
& =2 \text { if } \$ 25,000-\$ 49,999 \\
& =3 \text { if } \$ 50,000-\$ 74,999
\end{aligned}
$$$$
0.421
$$$$
0.337
$$$$
(0.494)
$$$$
0.044
$$$$
(0.473)
$$$$
(0.206)
$$$$
0.077
$$$$
0.173
$$$$
\text { (0.266) }
$$ 
Table 1. Continued

\begin{tabular}{|c|c|c|c|}
\hline $\begin{array}{l}\text { Variable/ } \\
\text { Question }\end{array}$ & Description & $\begin{array}{c}\text { Unweighted } \\
\text { Mean }^{\mathrm{a}}\end{array}$ & $\begin{array}{c}\text { Weighted } \\
\text { Mean }^{\text {b }}\end{array}$ \\
\hline & $=4$ if $\$ 75,000-\$ 99,999$ & $\begin{array}{c}0.163 \\
(0.369)\end{array}$ & $\begin{array}{c}0.203 \\
(0.402)\end{array}$ \\
\hline & $=5$ if $\$ 100,000-\$ 124,999$ & $\begin{array}{c}0.106 \\
(0.308)\end{array}$ & $\begin{array}{c}0.074 \\
(0.261)\end{array}$ \\
\hline & $=6$ if $\$ 125,000$ or more & $\begin{array}{c}0.290 \\
(0.454)\end{array}$ & $\begin{array}{c}0.195 \\
(0.396)\end{array}$ \\
\hline
\end{tabular}

OINCOME Portion of household income from off-farm sources

$$
\begin{aligned}
& =1 \text { if less than } 20 \% \\
& =2 \text { if } 20-39 \% \\
& =3 \text { if } 40-59 \% \\
& =4 \text { if } 60-79 \% \\
& =5 \text { if } 80 \% \text { or more }
\end{aligned}
$$

$\begin{array}{cc}0.446 & 0.275 \\ (0.498) & (0.447) \\ 0.154 & 0.127 \\ (0.361) & (0.333) \\ 0.189 & 0.180 \\ (0.392) & (0.384) \\ 0.087 & 0.196 \\ (0.282) & (0.397) \\ 0.122 & 0.221 \\ (0.328) & (0.415)\end{array}$

MANNAIS Do you believe NAIS should be a mandatory system?

$$
\begin{aligned}
& =0 \text { if no; } 1 \text { or } 2 \text { otherwise } \\
& =1 \text { if yes } \\
& =2 \text { if undecided }
\end{aligned}
$$$$
0.540
$$$$
0.624
$$$$
\text { (0.499) }
$$$$
\text { (0.484) }
$$$$
0.194
$$$$
0.165
$$

(0.396)

(0.371)

0.266

0.211

(0.442)

(0.408)

\section{REGIONS}

$\mathrm{CB}$

$\mathrm{NC}$

NP

NW

SE

SP

NAISPREM

AUCTIONS
US regions ${ }^{\mathrm{c}}$

$=1$ if corn belt (IL, IN, IA, MO, OH); 0 otherwise

$=1$ if northern crescent (MN, WI, CT, ME, MD MA, NH, NJ, NY, PA, RI, VT); 0 otherwise

$=1$ if northern plains $(\mathrm{KS}, \mathrm{NE}, \mathrm{ND}, \mathrm{SD}) ; 0$ otherwise

$=1$ if northwest $(\mathrm{AZ}, \mathrm{CA}, \mathrm{CO}, \mathrm{ID}, \mathrm{MT}, \mathrm{NV}, \mathrm{NM}$, OR, UT, WA, WY); 0 otherwise

$=1$ if southeast $(\mathrm{AL}, \mathrm{FL}, \mathrm{GA}, \mathrm{SC}, \mathrm{KY}, \mathrm{NC}, \mathrm{TN}$, VA, WV, AK, LA, MS); 0 otherwise

$=1$ if southern plains $(\mathrm{OK}, \mathrm{TX}) ; 0$ otherwise

$\begin{array}{cc}0.167 & 0.208 \\ (0.374) & (0.406) \\ 0.031 & 0.073 \\ & \\ (0.174) & (0.261) \\ 0.273 & 0.224 \\ (0.446) & (0.417) \\ 0.227 & 0.185\end{array}$

(0.419)

(0.388)

0.141

0.144

(0.349)

$(0.351)$

0.151

0.163

(0.358)

(0.370)

Are your operation's premise(s) currently registered in NAIS?

$$
=1 \text { if yes; } 0 \text { otherwise }
$$

Do you frequently use local auctions to market your operations output?

$$
=1 \text { if yes; } 0 \text { otherwise }
$$


Table 1. Continued

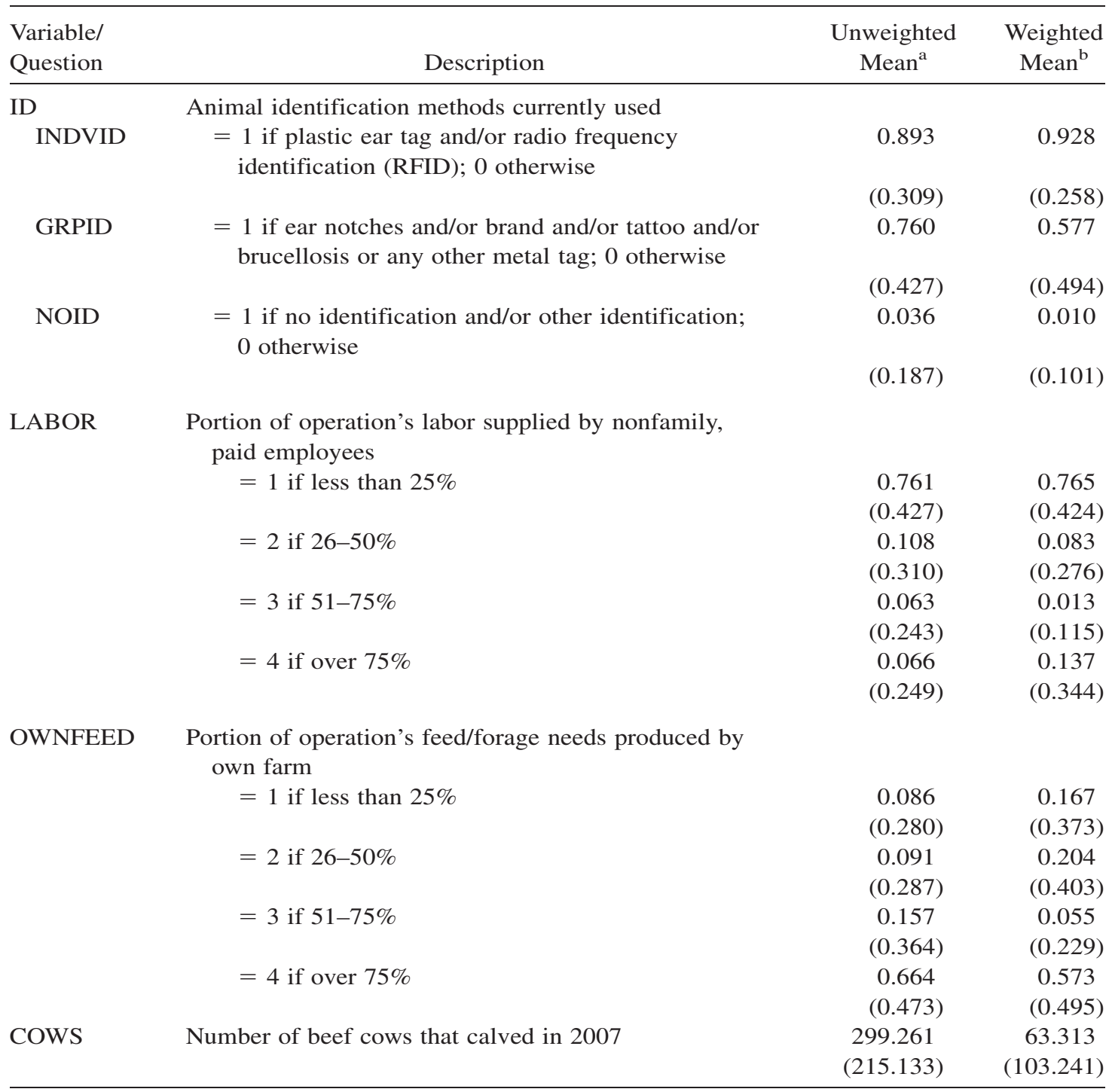

Note: Values in parentheses are standard deviations.

${ }^{a}$ Sample means before application of weights that adjust sample characteristics to match NASS cow-calf operation numbers.

${ }^{\mathrm{b}}$ Means calculated using weights that adjust sample characteristics to match NASS cow-calf operation numbers.

${ }^{\mathrm{c}}$ The production regions used in analysis were adjusted from USDA Economic Research Service (ERS) farm production regions combining the mountain and pacific regions, lake states and northeast region, and southeast region, Appalachia region, and delta states.

Cow-calf operations within the sample were larger than the general U.S. cow-calf operation numbers as reported by the National Agriculture Statistics Service (NASS). To correct for the differences in the sample and the population, poststratification weights were created based on 2007 beef cows that calved per operation data from NASS (Lusk and Rozan, 2008). We chose this variable because beef cows that calved per operation are likely to be highly related to producers' demographics, production practices, and perceptions regarding individual animal traceability. Following Lusk and Rozan (2008) to create weights, we placed each respondent into one of five operation size categories. ${ }^{5}$ Weights were created by dividing the frequency of U.S.

${ }^{5}$ Beef cows per operation categories included: 1-49, 50-99, 100-499, 500-999, and 1000+. 
cow-calf operations in each of the five size categories (as reported by NASS) by the fraction of cow-calf operations in the survey sample that fell in each of the five categories. To illustrate the effect of the weights on results, Table 1 reports weighted and unweighted means and standard deviations of the variables used in the analysis. Once weights were applied to the data, the mean beef cows per operation match those of the U.S. herd sizes. Because the weighted statistics are more reflective of the actual population and corrected imbalances in sampling ratios from the general population to the sample, all results reported in the remaining analysis use the derived weights.

\section{Procedures}

This article sought to build on the existing literature and prior traceability system studies by gathering and analyzing survey data from cowcalf producers to inform the discussion regarding implications of traceability system design and promotion. Producers' demographics, production practices, and perceptions will likely have large impacts on their current practices and decisions regarding traceability systems. Controlling for demographics is necessary for examining the relative impacts of demographics to the impacts of other factors like perceptions and current production practices. Some production methods may decrease support because producers would not like to share that information with the rest of the production chain, whereas some production methods may increase support because producers can use these claims to increase marketability. Some marketing methods may decrease support because producers may not see the need when they are marketing directly to consumers because the beef is already traceable. Although other marketing methods may increase support because producers can use these claims to increase marketability, producers' perceptions regarding important issues to the U.S. beef industry when designing a voluntary traceability system examined if producers are more concerned with issues such as disease implications or marketability. Perceptions regarding concerns to the U.S. beef industry when designing a voluntary traceability system may also impact support.
An evaluation of what type of cow-calf producer has their premises registered in NAIS was performed to determine the characteristics and perceptions of producers that led to their decision concerning premises registration in NAIS. To understand their current participation in NAIS, we asked participants: "Are your operation's premise(s) currently registered with USDA in the NAIS (National Animal Identification System)? YES or NO.” Responses to this question were analyzed with a binary Probit model. Following Greene (2003), let $y_{i}^{*}$ denote the true unknown choice for producer $i$ of whether or not to register their premises in NAIS and denote the observed variable with $y_{i}$. Then the relationship between the true and observed choice can be described with the threshold model (Roosen, Lusk, and Fox, 2001):

$$
\begin{array}{lll}
y_{i}=1 & \text { if } & y_{i}^{*}>0 \\
y_{i}=0 & \text { if } & y_{i}^{*} \leq 0
\end{array}
$$

Assuming that $y_{i}^{*}=\beta^{\prime} x_{i}+\varepsilon_{i}$ with $\varepsilon_{i} \sim N(0,1)$, the probabilities of observing $y_{i}$ are:

$$
\begin{aligned}
& \operatorname{Pr} o b\left(y_{i}=1 \mid x_{i}\right)=\Phi\left(\beta^{\prime} x_{i}\right) \\
& \operatorname{Pr} o b\left(y_{i}=0 \mid x_{i}\right)=1-\Phi\left(\beta^{\prime} x_{i}\right)
\end{aligned}
$$

where $\Phi(\cdot)$ is the standard normal distribution. A structural econometric model for the dependent variable in question is written as follows:

$$
y_{i}^{*}=\beta^{\prime} x_{i}+\varepsilon_{i}
$$

where $y_{i}^{*}=1(0)$ if a producer answered Yes (No), $\beta^{\prime}$ s are coefficients to be estimated, $x_{i}$ are demographics, production practices, and perceptions of the ith producer as shown in Table 1 and $\varepsilon_{i} \sim N(0,1)$.

The dependent and explanatory variables for the binary Probit for analyzing NAIS premises registrations were assumed to be the following:

$N A I S P R E M=Y R S R, E X P Y R S, N C B A, R C A L F$, COLLEGE, INCOME, OINCOME, MANNAIS, CB, NP, NW, SE, SP,
INDVID, GRPID, NOID, LABOR,
OWNFEED, COWS

where variables are defined as in Table 1 .

The marginal effects of the model are used to show statistically significant results and for 
interpretations of variables. That is, these marginal effects are evaluated at every observation and the sample average is used for the individual marginal effects of each explanatory variable (Greene, 2003). Following Greene (2003), the marginal effect of a change in the explanatory variable is:

$$
\frac{\partial E\left[y_{i} \mid x_{i}\right]}{\partial x_{i}}=\varphi\left(\beta^{\prime} x_{i}\right) \beta
$$

where $\varphi(t)$ is the standard normal density.

To evaluate producer views on issues and concerns underlying development of national, individual animal traceability systems, participants were asked a series of Likert scale questions. Measuring producers' views of the importance of monitoring/managing disease, increasing consumer confidence, enhancing marketability, assessing foreign markets, improving on-farm management, managing the supply chain, and enhancing food safety as related to a national, individual animal traceability system is critical because traceability systems that are most aligned with the preferences of cow-calf producers will experience higher voluntary participation. However, traceability systems based solely on cowcalf producer preferences may not maximize the nation's ability to respond to animal disease or meet alternative goals of nationwide traceability systems. Producers and animal health officials must be conscious that lower voluntary participation in a stringent system may well be better than higher voluntary participation in a weaker system for accomplishing many of the traceability system initiatives and goals.

Furthermore, identification of the concerns regarding cost to the participating producer, confidentiality of information, reliability of technology, liability to participating producer, nonparticipating firms benefiting, and failure of the system to meet stated goals will assist animal health officials in design and promotion of potential individual animal traceability systems.

As shown by summary statistics presented in Table 1, cow-calf producers vary widely in scale and production practices of their operations, so it is crucial to consider how producer specific demographics affect perceptions and concerns of these cow-calf producers. Ordered Probit models were used to estimate questions in which there was ranked responses as given in the following questions ${ }^{6}$ :

(i) "In designing a national, individual animal traceability system, how important are the following issues in the U.S. beef industry (please circle your answers where $1=$ entirely unimportant, 2 = unimportant, $3=$ neutral, $4=$ important, $5=$ very important)?"

(ii) "In designing a national, individual animal traceability system, how concerned are you regarding the following issues in the U.S. beef industry (where 1 = entirely unconcerned, $2=$ unconcerned, $3=$ neutral, $4=$ concerned, 5 = very concerned)?"

(iii) "Indicate your level of agreement with each of the following statements (where $1=$ strongly disagree, $2=$ disagree, $3=$ neutral, $4=$ agree, $5=$ strongly agree). Implementing individual animal traceability systems: (a) "is more cost-effective for larger cow-calf operations" (b) "results in more liability for cow-calf producers than cattle owners at other stages of production" (c) "is unnecessary if COOL (country of origin labeling) was implemented nationally" (d) "as a mandated system is exaggerated?"

The ordered Probit model is built around a latent regression (Greene, 2003). Following Green (2003) and Roosen, Lusk, and Fox (2001), let $z_{i}^{*}$ denote the true unknown preference of producer $i$ for a given perception concerning traceability and denote the observed variables with $z_{i}$. Then the relationship between the true and observed perception can be described with the threshold model:

${ }^{6} \mathrm{~A}$ factor analysis was performed on three sets of producer perception variables or 18 statements (questions in Table 3 ) before estimation. The scores from the 18 statements were factor-analyzed using principle component analysis with varimax rotation. Components were extracted until eigenvalues were less than or equal to 1.0 (Boxall and Adamowicz, 2002). The factor analysis identified three components across the given set of statements. However, these three components were not very informative because they simply consisted of each question in Table 3. Therefore, the factors were not used as explanatory variables in subsequent models. 


$$
\begin{array}{lll}
z_{i}=1 & \text { if } & z_{i}^{*}<0, \\
z_{i}=2 & \text { if } & 0<z_{i}^{*} \leq \mu_{1}, \\
z_{i}=3 & \text { if } & \mu_{1}<z_{i}^{*} \leq \mu_{2}, \\
z_{i}=4 & \text { if } & \mu_{2}<z_{i}^{*} \leq \mu_{3}, \\
z_{i}=5 & \text { if } & \mu_{3}<z_{i}^{*} .
\end{array}
$$

Assuming that $z_{i}^{*}=\beta^{\prime} x_{i}+\varepsilon_{i}$ with $\varepsilon_{i} \sim N(0.1)$, the probabilities of observing $z_{i}$ are:

$$
\text { (7) } \begin{aligned}
& \left.\operatorname{Pr} o b\left(y_{i}=1 \mid x_{i}\right)=1-\Phi\left(y^{\prime} x_{i}\right)=3 \mid x_{i}\right)=\Phi\left(\mu_{2}-\beta^{\prime} x_{i}\right)-\Phi\left(\mu_{1}-\beta^{\prime} x_{i}\right) \\
& \operatorname{Pr} o b\left(y_{i}=4 \mid x_{i}\right)=\Phi\left(\mu_{3}-\beta^{\prime} x_{i}\right)-\Phi\left(\mu_{2}-\beta^{\prime} x_{i}\right) \\
& \operatorname{Pr} o b\left(y_{i}=5 \mid x_{i}\right)=1-\Phi\left(\mu_{3}-\beta^{\prime} x_{i}\right)
\end{aligned}
$$

where $\Phi(\cdot)$ denotes the standard normal cumulative distribution function. A structural econometric model for the dependent variable in question is written as follows:

$$
z_{i}^{*}=\beta^{\prime} x_{i}+\varepsilon_{i}
$$

where $z_{i}=1,2,3,4$, or 5 as shown in Table 2, $\beta^{\prime}$ s are coefficients to be estimated and $x_{i}$ are

Table 2. Marginal Effects of the Binary Probit Analyzing National Animal Identification System Premises Registrations

\begin{tabular}{lc}
\hline Variable & Marginal Effect \\
\hline YRSR & -0.009 \\
NCBA & 0.086 \\
RCALF & -0.071 \\
COLLEGE & 0.332 \\
INCOME & -0.003 \\
OINCOME & -0.053 \\
MANNAIS & 0.182 \\
CB & 0.278 \\
NP & 0.213 \\
NW & 0.112 \\
SE & 0.339 \\
SP & 0.256 \\
AUCTIONS & -0.187 \\
INDVID & 0.373 \\
GRPID & 0.126 \\
NOID & -0.131 \\
LABOR & 0.005 \\
OWNFEED & -0.037 \\
COWS & -0.0003 \\
\hline
\end{tabular}

Note: Estimated coefficients are available on request. Likelihood ratio test (parameters equal to zero) was 88.445 ( $p<$ $0.0001)$. Marginal effect estimates are only shown for variables statistically significant at the $95 \%$ level. demographics, production practices, and perceptions of the $i$ th producer as shown in Table 1 .

The explanatory variables for the order Probits $(x)$ for evaluating producer views on issues and concerns underlying development of national, individual animal traceability systems were assumed to be the following:

$$
\begin{aligned}
x= & Y R S R, \text { EXPYRS, NCBA, RCALF, } \\
& \text { COLLEGE, INCOME, OINCOME, } \\
& \text { MANNAIS, CB, NP, NW, SE, SP, } \\
& \text { NAISPREM, INDVID, GRPID, NOID, } \\
& \text { LABOR, OWNFEED, COWS }
\end{aligned}
$$

where variables are defined as in Table 1.

Again, following Greene (2003), the marginal effects of changes in the explanatory variables are:

(10)

$$
\begin{aligned}
& \frac{\partial \operatorname{Pr} o b\left(z_{i}=1 \mid x_{i}\right)}{\partial x_{i}}=-\varphi\left(\beta^{\prime} x_{i}\right) \beta \\
& \frac{\partial \operatorname{Pr} o b\left(z_{i}=2 \mid x_{i}\right)}{\partial x_{i}} \\
& =\left[\varphi\left(-\beta^{\prime} x_{i}\right)-\varphi\left(\mu_{1}-\beta^{\prime} x_{i}\right)\right] \beta \\
& \frac{\partial \operatorname{Pr} o b\left(z_{i}=3 \mid x_{i}\right)}{\partial x_{i}} \\
& =\left[\varphi\left(\mu_{1}-\beta^{\prime} x_{i}\right)-\varphi\left(\mu_{2}-\beta^{\prime} x_{i}\right)\right] \beta \\
& \frac{\partial \operatorname{Pr} o b\left(z_{i}=4 \mid x_{i}\right)}{\partial x_{i}} \\
& =\left[\varphi\left(\mu_{2}-\beta^{\prime} x_{i}\right)-\varphi\left(\mu_{3}-\beta^{\prime} x_{i}\right)\right] \beta \\
& \frac{\partial \operatorname{Pr} o b\left(z_{i}=5 \mid x_{i}\right)}{\partial x_{i}}=\varphi\left(\mu_{3}-\beta^{\prime} x_{i}\right) \beta
\end{aligned}
$$

where $\varphi(t)$ is the standard normal density. As previously mentioned, the marginal effects of the models are used to show statistically significant results and for interpretations of variables. To determine if each level of the marginal effect estimate in each model is statistically different from zero, a Krinsky and Robb (1986) bootstrapping procedure was used to develop confidence intervals on the marginal effect estimates. The Krinsky and Robb approach was implemented using information readily available from the ordered Probit model: the estimates of the parameter vector and the estimated variancecovariance matrix (Park, Loomis, and Creel, 1991). The technique uses the information on the distribution of the parameter estimates contained in the variance-covariance matrix to approximate the distribution of the marginal effect. 


\section{Results}

\section{National Animal Identification System Premises Registration}

Table 2 provides marginal effect estimates for the characteristics of producers who have their premises registered with NAIS. The predictive ability of the model was measured by the correct predictions. The overall equation fit well with an $R_{P}^{2}$ equal to 0.653 .

Our sample has $38.4 \%$ (weighted data) indicating they have registered their premises with NAIS, which is reasonably consistent with current USDA estimates of $37.2 \%$ (USDA-APHIS, 2009). Estimates reveal that producer characteristics have statistically significant effects on whether producers decide to register their premises with NAIS. In particular, for every 5 years of additional experience, producers are $0.88 \%$ less likely to have their premises registered in NAIS. Membership in the National Cattlemen's Beef Association (NCBA) increases the likelihood of producers registering their premises by $8.65 \%$, whereas membership in the Ranchers and Cattlemen's Action Legal Fund (RCALF) decreases the likelihood of producers registering their premises by $7.12 \%$. Producers with a college degree are $33.23 \%$ more likely to have their premises registered. For every $\$ 25,000$ increase in pretax household income, producers are $0.28 \%$ less likely to register their premises. Increasing the proportion of off-farm income by $20 \%$ is associated with a $5.31 \%$ decrease in the likelihood of a producer registering their premises in NAIS. Producers who believe NAIS should be mandatory are $18.22 \%$ more likely to have premises registered. Likely producers who do not have their premises registered believe investments necessary to adopt NAIS practices are too risky under voluntary adoption.

Cow-calf operators in the corn belt, northern plains, northwest, southeast, and southern plains are $27.77 \%, 21.29 \%, 11.19 \%, 33.89 \%$, and $25.58 \%$, respectively, more likely than those in the northern crescent to have their operation's premises registered with NAIS. ${ }^{7}$ Producers using local

\footnotetext{
${ }^{7}$ The base region consists of the following states in the northern crescent region of the U.S.: MN, WI, CT, ME, MD, MA, NH, NJ, NY, PA, RI, and VT. This region comprises $3.70 \%$ of the survey population.
}

auctions to market their cattle are $18.73 \%$ less likely to have their premises registered. Individual and group identification on premises increases the likelihood of NAIS premise registration by $37.31 \%$ and $12.57 \%$, respectively, whereas no identification on premises decreases the likelihood of NAIS premise registration by $13.12 \%$. Increasing the proportion of hired, nonfamily labor on an operation by $25 \%$ is associated with a $0.49 \%$ decrease in the likelihood of the premise being registered. Increasing the proportion of feed/forage needs that an operation produces on their own farm by $25 \%$ is associated with a $3.67 \%$ decrease in the likelihood of producers registering their premises. Each additional 100 beef cows causes producers to be $2.9 \%$ less likely to register their premises in NAIS. These estimates identified what type of cow-calf producer likely registers (choose not to register) their premises. In summary, membership in NCBA or RCALF, education, region of operation, and current animal identification practices have a substantial impact on whether cow-calf producers register their premises with NAIS. Furthermore, it is evident that larger operations as identified by increased labor requirements and increased herd sizes are less likely to register their premises in NAIS. This may be the result of the perception of additional costs associated with the requirements of NAIS. Increasing the proportion of feed/forage needs that an operation produces on their own farm likely decreases premise registration because these producers believe their operations output is already traceable.

\section{Important Issues When Implementing \\ Traceability Systems}

Table 3 provides a summary of producer responses to 18 Likert scale questions. ${ }^{8,9}$ Producers

\footnotetext{
${ }^{8}$ It would have been preferable to model answers to these questions in a system with all equations being included as a result of the possible correlation between various questions attributable to potentially omitted covariates in each model; however, convergence constraints and software limitations restricted our ability to do so. Single-equation ordered Probit models were settled on because conclusions were not substantially changed as compared with subjective bivariate specifications and convergence was feasible.

${ }^{9}$ Five models were chosen to summarize perceptions with the other models being available on request.
} 
Table 3. Producer Responses Regarding Traceability Systems

\begin{tabular}{lccrrr}
\hline \multicolumn{5}{c}{ Important Issues When Designing a Traceability System $^{\mathrm{a}}$} \\
\hline & $\begin{array}{c}\text { Entirely } \\
\text { Unimportant }\end{array}$ & Unimportant & Neutral & Important & $\begin{array}{c}\text { Very } \\
\text { Important }\end{array}$ \\
\hline Monitoring/managing disease & $7.84 \%$ & $3.16 \%$ & $16.33 \%$ & $37.49 \%$ & $35.17 \%$ \\
Increasing consumer confidence & $8.02 \%$ & $6.31 \%$ & $18.67 \%$ & $38.97 \%$ & $28.04 \%$ \\
Enhancing marketability & $6.35 \%$ & $8.56 \%$ & $18.09 \%$ & $47.65 \%$ & $19.35 \%$ \\
Maintaining current foreign markets & $8.43 \%$ & $10.62 \%$ & $8.77 \%$ & $34.11 \%$ & $38.08 \%$ \\
Accessing foreign markets & $6.36 \%$ & $6.14 \%$ & $18.33 \%$ & $34.25 \%$ & $34.93 \%$ \\
Improving on-farm management & $13.77 \%$ & $9.11 \%$ & $18.39 \%$ & $39.78 \%$ & $18.95 \%$ \\
Managing the supply chain & $11.53 \%$ & $7.62 \%$ & $32.59 \%$ & $28.50 \%$ & $19.76 \%$ \\
\hline
\end{tabular}

\begin{tabular}{lccccc}
\hline \multicolumn{5}{c}{ Concerns When Designing a Traceability System } \\
\hline \multicolumn{7}{c}{$\begin{array}{c}\text { Entirely } \\
\text { Unconcerned }\end{array}$} & $\begin{array}{c}\text { Unconcerned } \\
\text { Neutral }\end{array}$ & $\begin{array}{c}\text { Concerned } \\
\text { Concerned }\end{array}$ \\
\hline Cost to participating producer & $9.50 \%$ & $2.80 \%$ & $22.01 \%$ & $33.47 \%$ & $32.23 \%$ \\
Confidentiality of information & $12.36 \%$ & $4.03 \%$ & $17.53 \%$ & $32.22 \%$ & $33.85 \%$ \\
Reliability of technology & $11.77 \%$ & $7.68 \%$ & $15.71 \%$ & $27.81 \%$ & $37.03 \%$ \\
Liability to participating producer & $9.45 \%$ & $5.44 \%$ & $18.83 \%$ & $21.08 \%$ & $45.21 \%$ \\
Nonparticipating firms benefiting & $7.63 \%$ & $9.77 \%$ & $16.87 \%$ & $32.73 \%$ & $33.00 \%$ \\
Failure of system to meet stated goals & $10.11 \%$ & $10.57 \%$ & $29.70 \%$ & $21.05 \%$ & $28.57 \%$ \\
\hline
\end{tabular}

Implementing Individual Animal Traceability Systems ${ }^{\mathrm{c}}$

\begin{tabular}{lccccc}
\hline & $\begin{array}{c}\text { Strongly } \\
\text { Disagree }\end{array}$ & Disagree & Neutral & Agree & $\begin{array}{c}\text { Strongly } \\
\text { Agree }\end{array}$ \\
\hline $\begin{array}{l}\text { "is more cost-effective for larger } \\
\text { cow-calf operations." }\end{array}$ & $10.56 \%$ & $21.29 \%$ & $27.15 \%$ & $25.09 \%$ & $15.92 \%$ \\
$\begin{array}{c}\text { "results in more liability for cow-calf } \\
\text { producers than cattle owners at other } \\
\text { stages of production." }\end{array}$ & $5.46 \%$ & $18.18 \%$ & $20.74 \%$ & $29.64 \%$ & $25.98 \%$ \\
$\begin{array}{l}\text { "is unnecessary if COOL (country of } \\
\text { origin labeling) was implemented } \\
\text { nationally." }\end{array}$ & $15.00 \%$ & $8.24 \%$ & $27.61 \%$ & $20.50 \%$ & $28.66 \%$ \\
$\begin{array}{l}\text { "as a mandated system is exaggerated } \\
\text { in need." }\end{array}$ & $6.46 \%$ & $16.12 \%$ & $21.88 \%$ & $31.67 \%$ & $23.87 \%$ \\
\hline
\end{tabular}

a, b, and ${ }^{c}$ were asked using 5-point Likert scales of entirely unimportant (1) to very important (5), entirely unconcerned (1) to very concerned (5), and strongly disagree (1) to strongly agree (5), respectively.

believe that the most important issue to the U.S. beef industry in designing a national, individual animal traceability system is monitoring/managing disease with over $72 \%$ of producers ranking this as important or very important. Maintaining current foreign markets, accessing foreign markets, and increasing consumer confidence were seen as important (important or very important) as indicated by over $72 \%, 69 \%$, and $67 \%$ of producers, respectively. This shows that producers are dually concerned with disease implications and marketability of their beef cattle when considering the design of a traceability system.
Table 4 presents the marginal effect estimates for how important producers feel traceability is for monitoring/managing disease and for increasing consumer confidence. In particular, it was constructive to interpret some of the estimates that appeared to be the main driver of producers' perceptions.

Producers who are members of the NCBA or RCALF are $13.15 \%$ and $9.01 \%$, respectively, more likely to respond that traceability is very important for monitoring/managing disease. Cow-calf operators in the northwest and southeast, $34.93 \%$ and $19.91 \%$, respectively, are more 
Table 4. Ordered Probit Marginal Effects: Importance of Traceability

\begin{tabular}{lccccc}
\hline & $\begin{array}{c}\text { Entirely } \\
\text { Unimportant }\end{array}$ & Unimportant & Neutral & Important & $\begin{array}{c}\text { Very } \\
\text { Important }\end{array}$ \\
\cline { 2 - 5 } Variable & \multicolumn{3}{c}{ Importance of Traceability for Monitoring/Managing Disease } \\
\hline YRSR & 0.011 & 0.003 & 0.011 & 0.007 & -0.033 \\
EXPYRS & 0.010 & 0.003 & 0.010 & 0.007 & -0.031 \\
NCBA & -0.043 & -0.014 & -0.045 & -0.029 & 0.132 \\
RCALF & -0.030 & -0.010 & -0.031 & -0.020 & 0.090 \\
INCOME & -0.006 & -0.002 & -0.006 & -0.004 & 0.018 \\
OINCOME & -0.024 & -0.008 & -0.025 & -0.016 & 0.071 \\
MANNAIS & -0.036 & -0.012 & -0.038 & -0.024 & 0.111 \\
CB & -0.020 & -0.007 & -0.021 & -0.014 & 0.062 \\
NP & 0.010 & 0.003 & 0.010 & 0.007 & -0.030 \\
NW & -0.115 & -0.037 & -0.120 & -0.077 & 0.349 \\
SE & -0.066 & -0.021 & -0.069 & -0.044 & 0.199 \\
SP & -0.010 & -0.003 & -0.011 & -0.007 & 0.031 \\
NAISPREM & -0.008 & -0.002 & -0.008 & -0.005 & 0.024 \\
AUCTIONS & -0.005 & -0.002 & -0.005 & -0.003 & 0.014 \\
INDVID & -0.086 & -0.027 & -0.090 & -0.057 & 0.260 \\
GRPID & -0.108 & -0.034 & -0.112 & -0.072 & 0.327 \\
NOID & -0.122 & -0.039 & -0.127 & -0.082 & 0.370 \\
LABOR & 0.010 & 0.003 & 0.010 & 0.007 & -0.030 \\
OWNFEED & -0.018 & -0.006 & -0.019 & -0.012 & 0.055 \\
COWS & -0.00003 & -0.00001 & -0.00003 & -0.00002 & 0.0001 \\
\hline
\end{tabular}

\begin{tabular}{lrrrrr}
\hline & & Importance of Traceability & for Increasing Consumer Confidence \\
YRSR & -0.006 & -0.004 & -0.008 & -0.006 & 0.025 \\
EXPYRS & 0.006 & 0.004 & 0.008 & 0.006 & -0.023 \\
NCBA & -0.004 & -0.003 & -0.005 & -0.004 & 0.015 \\
RCALF & 0.004 & 0.003 & 0.006 & 0.004 & -0.018 \\
COLLEGE & -0.013 & -0.010 & -0.018 & -0.013 & 0.053 \\
INCOME & -0.017 & -0.013 & -0.023 & -0.017 & 0.070 \\
OINCOME & -0.016 & -0.012 & -0.021 & -0.016 & 0.064 \\
MANNAIS & -0.030 & -0.022 & -0.040 & -0.029 & 0.121 \\
CB & -0.064 & -0.047 & -0.086 & -0.063 & 0.259 \\
NP & -0.093 & -0.068 & -0.126 & -0.092 & 0.379 \\
NW & -0.070 & -0.051 & -0.094 & -0.068 & 0.283 \\
SE & -0.071 & -0.052 & -0.096 & -0.070 & 0.289 \\
SP & -0.035 & -0.026 & -0.048 & -0.035 & 0.144 \\
NAISPREM & 0.009 & 0.007 & 0.012 & 0.009 & -0.037 \\
AUCTIONS & 0.011 & 0.008 & 0.015 & 0.011 & -0.044 \\
INDVID & -0.067 & -0.049 & -0.091 & -0.066 & 0.273 \\
GRPID & -0.048 & -0.035 & -0.065 & -0.047 & 0.195 \\
NOID & -0.060 & -0.043 & -0.080 & -0.058 & 0.242 \\
LABOR & 0.015 & 0.011 & 0.021 & 0.015 & -0.063 \\
OWNFEED & -0.0002 & -0.0002 & -0.0003 & -0.0002 & 0.001 \\
COWS & -0.0001 & -0.0001 & -0.0001 & -0.0001 & 0.0004 \\
\hline
\end{tabular}

Note: Estimated coefficients are available upon request. Likelihood ratio tests (parameters equal to zero) for the importance of traceability for monitoring/managing disease and importance of traceability for increasing consumer confidence models were 76.542 (prob < 0.0001) and 71.396 (prob < 0.0001), respectively. Marginal effect estimates are only shown for variables statistically significant at the $95 \%$ level. 
likely than those in the northern crescent to respond that traceability is very important for monitoring/managing disease. However, producers in the northern plains are $2.96 \%$ less likely to respond that traceability is very important for monitoring/ managing disease. Producers with premises registered in NAIS are $2.37 \%$ more likely to respond that traceability is very important for monitoring/managing disease. Similarly, producers using local auctions to market cattle are $1.43 \%$ more likely to respond that traceability is very important for monitoring/managing disease. Individual, group, or no identification on premises increases the likelihood of producers responding that individual animal identification is important for managing/monitoring disease.

Similar results were generally found for how important producers felt individual animal traceability was for increasing consumer confidence. However, some noticeable differences in producers' responses to this question were that membership in RCALF causes producers to be $1.75 \%$ less likely to respond that traceability is important for increasing consumer confidence. Furthermore, producers with premises registered in NAIS are $3.66 \%$ less likely to respond that traceability is very important for increasing consumer confidence, whereas producers using local auctions to market cattle are $4.41 \%$ less likely to respond that traceability is very important for increasing consumer confidence.

\section{Producer Concerns When Implementing Traceability Systems}

Next, we evaluated if previously identified concerns regarding traceability within the beef industry were still of top apprehension to participation or have producers perceptions shifted. Table 3 indicates when it came to concerns of implementation of traceability systems, producers were concerned (responded as either concerned or very concerned) with cost $(65.70 \%)$, liability $(66.07 \%)$, reliability of technology $(64.84 \%)$, failure of system to meet stated goals (66.29\%), confidentiality of information $(65.73 \%)$, and nonparticipating firms benefiting (49.62\%). These results are concurrent with Schroeder et al. (2009) who found that larger firms that have large numbers of animals indicate common technology that will operate effectively (error-free) at the speed of commerce is essential. Schroeder et al. (2009) also found that producers were concerned with having multiple individual data banks, which may make coordination and communication across data banks problematic in which traceability would be slowed or even impeded. Furthermore, they found that there were concerns of nonadopters gaining at the expense of adopters of the technology. However, even in the presence of a free-rider problem, animal herd health and management can be improved through traceability. The issue of confidentiality of information has long been a concern voiced by industry participants (Bailey and Slade, 2004; Schroeder et al., 2009).

Table 5 shows the marginal effect estimates for how concerned producers were with the costs and liability associated with traceability systems. Membership in NCBA causes producers to be $4.74 \%$ more likely to respond as being very concerned with cost to the participating producers, whereas membership in RCALF causes producers to be $23.30 \%$ more likely to respond being very concerned with cost. Producers using local auctions to market cattle are $12.81 \%$ more likely to respond as being very concerned with cost to the participating producers. For each additional 100 head of cattle, producers are $4.8 \%$ more likely to respond as being very concerned with cost. Although larger operations indicate a concern with cost, their relative cost is likely less than for larger producers. Schroeder et al. (2009) find that economies of size exist because larger operations have a lower per-animal cost compared with the smallest operations. Also, operations that currently tag their cattle have lower costs, which is likely the result of the incremental cost of using their labor and facilities is lower than hiring tagging done by a third party.

Membership in NCBA causes producers to be $11.25 \%$ less likely to respond as being very concerned with liability to the participating producers. Here, membership in RCALF only causes producers to be $8.61 \%$ more likely to respond as being very concerned with liability. Producers using local auctions to market cattle are $6.91 \%$ less likely to respond as being very concerned with liability to the participating producers. For each additional 100 head of 
Table 5. Ordered Probit Marginal Effects: Concerns with Traceability

\begin{tabular}{|c|c|c|c|c|c|}
\hline \multirow[b]{2}{*}{ Variable } & $\begin{array}{c}\text { Entirely } \\
\text { Unconcerned }\end{array}$ & Unconcerned & Neutral & Concerned & Very Concerned \\
\hline & \multicolumn{5}{|c|}{ Concerns Regarding Traceability System Cost } \\
\hline YRSR & -0.004 & -0.0003 & -0.008 & $-0.004 *$ & 0.016 \\
\hline EXPYRS & 0.003 & 0.0002 & 0.004 & $0.002 *$ & -0.010 \\
\hline NCBA & -0.013 & -0.001 & -0.022 & $-0.012 *$ & 0.047 \\
\hline RCALF & -0.063 & -0.005 & -0.108 & $-0.057^{*}$ & 0.233 \\
\hline COLLEGE & 0.076 & 0.005 & 0.130 & $0.068^{*}$ & -0.279 \\
\hline INCOME & -0.008 & -0.001 & -0.014 & $-0.007 *$ & 0.031 \\
\hline OINCOME & -0.011 & -0.001 & -0.019 & $-0.010^{*}$ & 0.041 \\
\hline MANNAIS & -0.018 & -0.001 & -0.031 & $-0.016^{*}$ & 0.066 \\
\hline $\mathrm{CB}$ & -0.074 & -0.005 & -0.126 & $-0.066^{*}$ & 0.271 \\
\hline NP & -0.041 & -0.003 & -0.070 & $-0.037 *$ & 0.150 \\
\hline NW & -0.033 & -0.002 & -0.057 & $-0.030 *$ & 0.122 \\
\hline SE & -0.110 & -0.008 & -0.189 & $-0.099 *$ & 0.406 \\
\hline SP & -0.104 & -0.007 & -0.177 & $-0.093^{*}$ & 0.381 \\
\hline NAISPREM & 0.013 & 0.001 & 0.022 & $0.012 *$ & -0.048 \\
\hline AUCTIONS & -0.035 & -0.002 & -0.060 & $-0.031 *$ & 0.128 \\
\hline INDVID & 0.066 & 0.005 & 0.113 & $0.059 *$ & -0.242 \\
\hline GRPID & -0.069 & -0.005 & -0.119 & $-0.062 *$ & 0.255 \\
\hline NOID & 0.012 & 0.001 & 0.020 & $0.011 *$ & -0.044 \\
\hline LABOR & 0.016 & 0.001 & 0.027 & $0.014 *$ & -0.058 \\
\hline OWNFEED & -0.010 & -0.001 & -0.016 & $-0.009 *$ & 0.035 \\
\hline \multirow[t]{2}{*}{ COWS } & -0.0001 & -0.00001 & -0.0002 & $-0.0001 *$ & 0.0005 \\
\hline & \multicolumn{5}{|c|}{ Concerns Regarding Traceability System Liability } \\
\hline YRSR & -0.010 & -0.005 & -0.009 & -0.006 & 0.030 \\
\hline EXPYRS & -0.005 & -0.002 & -0.005 & -0.003 & 0.015 \\
\hline NCBA & 0.036 & 0.019 & 0.036 & 0.021 & -0.112 \\
\hline RCALF & -0.028 & -0.014 & -0.028 & -0.016 & 0.086 \\
\hline COLLEGE & 0.076 & 0.039 & 0.076 & 0.045 & -0.236 \\
\hline INCOME & -0.010 & -0.005 & -0.010 & -0.006 & 0.030 \\
\hline OINCOME & 0.008 & 0.004 & 0.008 & 0.005 & -0.024 \\
\hline MANNAIS & 0.001 & 0.0003 & 0.001 & 0.0004 & -0.002 \\
\hline $\mathrm{CB}$ & -0.072 & -0.037 & -0.071 & -0.042 & 0.222 \\
\hline NP & -0.140 & -0.072 & -0.139 & -0.082 & 0.433 \\
\hline NW & -0.032 & -0.016 & -0.032 & -0.019 & 0.099 \\
\hline SE & -0.207 & -0.107 & -0.206 & -0.121 & 0.641 \\
\hline SP & -0.099 & -0.051 & -0.098 & -0.058 & 0.306 \\
\hline NAISPREM & -0.012 & -0.006 & -0.012 & -0.007 & 0.038 \\
\hline AUCTIONS & 0.022 & 0.012 & 0.022 & 0.013 & -0.069 \\
\hline INDVID & 0.115 & 0.059 & 0.114 & 0.067 & -0.355 \\
\hline GRPID & -0.059 & -0.031 & -0.059 & -0.035 & 0.184 \\
\hline NOID & 0.093 & 0.048 & 0.092 & 0.054 & -0.288 \\
\hline LABOR & 0.023 & 0.012 & 0.023 & 0.013 & -0.071 \\
\hline OWNFEED & -0.022 & -0.012 & -0.022 & -0.013 & 0.069 \\
\hline COWS & 0.0001 & 0.00003 & 0.0001 & 0.00004 & -0.0002 \\
\hline
\end{tabular}

Note: Estimated coefficients are available on request. Likelihood ratio tests (parameters equal to zero) for the concerns regarding traceability system cost and concerns regarding traceability system liability models were $54.513(p<0.0001)$ and $45.333(p=$ 0.0016), respectively. Marginal effect estimates are only shown for variables statistically significant at the $95 \%$ level. An asterisk denotes a marginal effect that is not statistically significant at the $95 \%$ level. 
cattle, producers are $2 \%$ less likely to respond as being very concerned with liability to the participating producers.

\section{Country of Origin Labeling and Traceability in the Beef Industry}

The NAIS and other proposed individual, animal traceability systems are not COOL systems. Although there are some similarities in the two programs, the information requirements for NAIS and related programs are different from the requirements of COOL. As previously defined, NAIS is an information system, whereas COOL is defined by the USDA-Agricultural Marketing Service (2009, p. 2658) as a labeling law that "requires retailers to notify their customers of the country of origin of covered commodities." Therefore, COOL is considered a marketing tool. Table 3 reveals that $49.16 \%$ of cow-calf producers believe COOL is more important than a proposed traceability system. Table 6 shows the marginal effect estimates of producers' perceptions concerning COOL implementation and traceability. Membership in NCBA causes producer to be $21.48 \%$ less likely to agree that traceability is unneeded if COOL was implemented, whereas producers who are members of RCALF are $8.97 \%$ more likely to agree that traceability is unneeded if COOL was implemented nationally. Cow-calf operators in the northern plains, northwest, and southeast are $11.81 \%, 13.65 \%$, and $34.21 \%$, respectively, more likely than those in the northern crescent to agree that traceability is unneeded if COOL was implemented nationally, whereas producers in the corn belt and southern plains are $2.79 \%$ and $9 \%$, respectively, less likely to agree that traceability is unneeded if COOL was implemented nationally. Individual and group identification on premises causes producers to be $9.09 \%$ and $3.45 \%$, respectively, less likely to agree that traceability is unneeded if COOL was implemented nationally, whereas

Table 6. Ordered Probit Marginal Effects: Traceability and Country of Origin Labeling

\begin{tabular}{lccccc}
\hline & $\begin{array}{l}\text { Strongly } \\
\text { Disagree }\end{array}$ & Disagree & Neutral & Agree & $\begin{array}{c}\text { Strongly } \\
\text { Agree }\end{array}$ \\
\cline { 2 - 6 } Variable & & Traceability & Is & Unnecessary & if \\
YRSR & -0.032 & -0.006 & -0.010 & 0.007 & 0.041 \\
EXPYRS & 0.001 & 0.0002 & 0.0003 & -0.0002 & -0.001 \\
NCBA & 0.167 & 0.031 & 0.053 & -0.036 & -0.215 \\
RCALF & -0.069 & -0.013 & -0.022 & 0.015 & 0.090 \\
COLLEGE & 0.080 & 0.015 & 0.026 & -0.018 & -0.104 \\
INCOME & 0.026 & 0.005 & 0.008 & -0.006 & -0.033 \\
OINCOME & 0.021 & 0.004 & 0.007 & -0.005 & -0.027 \\
MANNAIS & 0.046 & 0.009 & 0.015 & -0.010 & -0.059 \\
CB & 0.022 & 0.004 & 0.007 & -0.005 & -0.028 \\
NP & -0.092 & -0.017 & -0.029 & 0.020 & 0.118 \\
NW & -0.106 & -0.020 & -0.034 & 0.023 & 0.137 \\
SE & -0.265 & -0.050 & -0.085 & 0.058 & 0.342 \\
SP & 0.070 & 0.013 & 0.022 & -0.015 & -0.090 \\
NAISPREM & -0.055 & -0.010 & -0.018 & 0.012 & 0.070 \\
AUCTIONS & -0.011 & -0.002 & -0.003 & 0.002 & 0.014 \\
INDVID & 0.070 & 0.013 & 0.023 & -0.015 & -0.091 \\
GRPID & 0.027 & 0.005 & 0.009 & -0.006 & -0.035 \\
NOID & -0.019 & -0.004 & -0.006 & 0.004 & 0.024 \\
LABOR & 0.046 & 0.009 & 0.015 & -0.010 & -0.059 \\
OWNFEED & 0.038 & 0.007 & 0.012 & -0.008 & -0.050 \\
COWS & -0.00003 & -0.00001 & -0.00001 & 0.00001 & 0.00003 \\
\hline Not E & & & & & \\
\hline
\end{tabular}

Note: Estimated coefficients are available on request. Likelihood ratio test (parameters equal to zero) for the traceability is unnecessary if country of origin labeling (COOL) was implemented nationally model was $85.333(p<0.0001)$. Marginal effect estimates are only shown for variables statistically significant at the $95 \%$ level. 
no identification on premises increases the likelihood by $2.41 \%$ of producers agreeing that traceability is unneeded if COOL was implemented nationally.

\section{Conclusions}

Individual animal traceability systems that are attractive to producers as well as meet the goals that they were designed for have the potential to experience higher voluntary participation. A majority of the past research has sought to analyze consumers' perceptions toward voluntary traceability; however, there has been little research on producers' perceptions toward this same traceability. This has illustrated the need for taking producers' perceptions into account when designing, promoting, and imposing traceability systems.

In this study, we estimated the relative importance of producer characteristics on whether they chose to participate in the NAIS. Results suggest that producers who are members of the NCBA are more likely to register their premises, whereas membership in the RCALF decreases the likelihood of producers registering their premises. Furthermore, additional experience in raising beef cattle decreases the likelihood of producers registering their premises in NAIS. An important distinction that was found through this study was that producers using local auctions to market cattle are less likely to have their premises registered. This being said, there becomes a need by governing agencies of traceability programs to better meet the needs of this large group of producers. As expected, individual and group identification on premises increases the likelihood of NAIS premise registration, whereas no identification on premises decreases the likelihood of NAIS premise registration. This suggests that premises registrations could further be increased by producers using individual or group identification if they believe that traceability systems complement, not add redundancy and added layers of work, to current industry practices (Schroeder et al., 2009).

Producers who believe NAIS should be mandatory are more likely to have premises registered. Under a mandatory traceability system, investment must be made by all firms. Producers believing traceability should be mandatory likely believe they would have a competitive advantage under this regime. Promotion needs to emphasize the ability of traceability systems for animal health management, crisis management, adding credence attributes to food labels, enhancing trade, and various other potential benefits. Eliminating the uncertainty regarding the benefits of NAIS and other traceability systems and indicating how traceability practices can become part of business may reassure industry participants and increase participation rate. Furthermore, faster adoption rates, especially for smaller firms in industry, would likely indicate what direction to move in terms of adding or not adding traceability systems.

Results of this study also suggest that cowcalf producers believe that the most important issue to the U.S. beef industry in designing a national, individual animal traceability system is monitoring/managing disease with maintaining current foreign markets, accessing foreign markets, and increasing consumer confidence as also important. This showed that producers are dually concerned with disease implications and marketability of their beef cattle when considering the design of a traceability system. Similarly, Schroeder et al. (2009) found that there was a strong belief by some industry participants that NAIS is needed to ensure consumer confidence in our products.

Producers were equally concerned with cost, liability to the participating producer, reliability of technology, failure of system to meet stated goals, and confidentiality of information when implementing traceability systems. As expected, producers using local auctions to market cattle and producers with larger operations are more likely to respond being very concerned with cost. On the other hand, producers using local auctions and producers with larger operations were less likely to respond to being very concerned with liability to participating producers.

Producers throughout different geographic regions of the U.S. have differing opinions on whether traceability is unneeded if COOL was implemented nationally. Cow-calf operators in the northern plains (KS, NE, ND, SD), northwest (AZ, CA, CO, ID, MT, NV, NM, OR, UT, WA, WY), and southeast (AL, FL, GA, SC, KY, 
NC, TN, VA, WV, AK, LA, MS) are more likely than those in the northern crescent (MN, WI, CT, ME, MD, MA, NH, NJ, PA, RI, VT) to agree that traceability is unneeded if COOL was implemented nationally, whereas producers in the corn belt (IL, IA, MO, OH) and southern plains (OK, TX) are less likely than those in the northern crescent to agree that traceability is unneeded if COOL was implemented nationally. These differences may be explained by the status of statewide traceability initiatives. First, this is evident in the NAIS premises registrations in individual states ranging from $2.7 \%$ to $100 \%$ (USDA-APHIS, 2009). Furthermore, industry associations or producer groups have been responsible for introducing industrywide private sector traceability programs. Many of these U.S. private industry associations or producer group traceability systems tend to be motivated by economic incentives, not government traceability regulation. These private systems allow for the verification of many USDA-accredited claims such as age and source verification, organic, natural, etc. On the private, state, and national level, the USDA has used Process Verified Programs (PVP) and Quality Assessment Programs (QSA) that have been historically used for verification purposes in many industries and for a variety of products. In the case of U.S. beef cattle, the USDA has established PVPs and QSAs to ensure the credibility and authenticity of the process claims being made about traceable beef products. This includes claims such as age and source verified, organic, etc. Currently, PVP and QSA programs exist to back these claims and traceability systems are implicit in PVP and QSA programs for ensuring credibility and authenticity. Some countries require U.S. beef exporters to be accredited under a USDA Export Verification Program.

Individual and group identification on premises causes producers to be less likely to agree that traceability is unneeded if COOL was implemented nationally, whereas no identification on premises increases the likelihood of producers agreeing that traceability is unneeded if COOL was implemented. Therefore, promotion of individual animal traceability should emphasize that COOL is a marketing tool and that COOL and traceability can complement each other in the industry.
As animal identification becomes more important for serving functions within the beef industry, it becomes imperative for governing entities of traceability programs to be proactive in giving an identity to existing and proposed traceability systems to aid in increasing voluntary participation. It was the goal of this study to add valuable information in future efforts to enhance NAIS or other individual animal identification programs involving U.S. cow-calf producers. Future work may focus on how cow-calf producers' perception change if and when traceability becomes mandatory; requiring all U.S. producers to participate. Furthermore, examining the characteristics that describe the most optimistic and pessimistic forecasters of NAIS participation may provide a better sense of how NAIS and related traceability systems should be promoted to enhance voluntary participation.

[Received July 2010; Accepted February 2010.]

\section{References}

Bailey, D., and J. Slade. "Factors Influencing Support for a National Animal Identification System for Cattle in the United States." Paper presented at American Agricultural Economics Association Annual Meeting, Denver, CO, August 1-4, 2004.

Becker, G.S. Animal Identification and Meat Traceability. Congressional Research Report prepared for members and committees of Congress. Washington, DC, January 18, 2007.

Boxall, P.C., and W.L. Adamowicz. "Understanding Heterogeneous Preferences in Random Utility Models: A Latent Class Approach.” Environmental and Resource Economics 23(2002):421-46.

Breiner, S.J. "Perceptions and Attitudes of CowCalf Producers toward Emerging Technologies and Policy Issues in the Beef Cattle Industry." MS thesis, Kansas State University, 2007.

Buhr, B.L. 2003. Traceability, Trade and COOL: Lessons from the EU Meat and Poultry Industry. Working Paper, International Agricultural Trade Research Consortium no. 03-5. Internet site: http:// purl.umn.edu/14577 (Accessed July 7, 2009).

Bulut, H., and J.D. Lawrence. "Meat Slaughter and Processing Plants' Traceability Levels Evidence from Iowa." Paper presented at NCR-134 Conference on Applied Commodity Price Analysis, Forecasting, and Market Risk Management, Chicago, IL, April 16-17, 2007. 
Cattle Network. 2008. "Five Minutes with Dr. John Wiemers, USDA, APHIS, NAIS.” Internet site: www.cattlenetwork.com/content.asp?ContentId = 194952 (Accessed January 5, 2008).

Dickinson, D and D. Bailey. "Meat Traceability: Are US Consumers Willing to Pay for It?" Journal of Agriculture and Resource Economics 27,2(2002):348-64.

Dickinson, D.L., J.E. Hobbs, and D. Bailey. "A Comparison of US and Canadian Consumers' Willingness to Pay for Red-Meat Traceability." Paper presented at American Agricultural Economics Association Annual Meeting, Montreal, Canada, July 27-30, 2003.

Golan, E., B. Krissoff, F. Kuchler, L. Calvin, K. Nelson, and G. Price. Traceability in the US Food Supply: Economic Theory and Industry Studies. Washington, DC: US Department of Agriculture, Economic Research Service for Agr. Econ. Rep. 830, March 2004.

Greene, W.H. Econometric Analysis. 5th ed. Upper Saddle River, NJ: Prentice-Hall, Inc., 2003.

Gregory, A. "Optimal Economic Design of Mail Surveys: Influences of Response Rates and the Impact of Responses to a Second Mailing." PhD dissertation, Kansas State University, 2008.

Krinsky, I., and A.L. Robb. "On Approximating the Statistical Properties of Elasticities." The Review of Economics and Statistics 64(1986): 715-19.

Lusk, J., and A. Rozan. "Public Policy and Endogenous Beliefs: The Case of Genetically Modified Food." Journal of Agricultural and Resource Economics 33,2(2008):270-89.

Murphy, R.G.L., D.L. Pendell, and G.C. Smith. "Lessons from the Canadian Cattle Industry for Developing the National Animal Identification System." International Food and Agribusiness Management Review 12,2(2009):1-18.

Park, T., J. Loomis, and M. Creel. "Confidence Intervals for Evaluating Benefits from Dichotomous Choice Contingent Valuation Studies." Land Economics 67,1(1991):64-73.

Roosen, J., J. Lusk, and J. Fox. "Consumer Demand for and Attitudes toward Alternative Beef Labeling Strategies in France, Germany, and the UK." Paper presented at American Agricultural Economics Association annual meeting, Chicago, IL, August 5-8, 2001.

Saatkamp, H.W., A.A. Dijkhuizen, R. Geers, R.B.M. Huime, J.P.T.M. Noordhuizen, and V. Goedseels. "Economic Evaluation of National Identification and Recording Systems for Pigs in Belgium." Preventive Veterinary Medicine 30(1997):121-35.

Saatkamp, H.W., R. Geersa, J.P.T.M. Noordhuizenb, A.A. Dijkhuizenc, R.B.M. Huirne, and V. Goedseels. "National Identification and Recording Systems for Contagious Animal Disease Control." Livestock Production Science 43(1995):253-64.

Schroeder, T.C., D.A. Blasi, G.W. Brester, C. Crosby, K.C. Dhuyvetter, J. Freeborn, D.L. Pendell, G.C. Smith, J. Stroade, and G.T. Tonsor. 2009. "Benefit Cost Analysis of the National Animal Identification System." Report for U.S. Department of Agriculture, Animal and Plant Health Inspection, Internet site: http://animalid.aphis.usda.gov/nais/ naislibrary/documents/plans_reports/Benefit_ Cost_Analysis_NAIS.pdf (Accessed November 13, 2009).

Souza-Monteiro, D.M., and J.A. Caswell. "The Economics of Implementing Traceability in Beef Supply Chains: Trends in Major Producing and Trading Countries." Working paper, Department of Resource Economics, University of Massachusetts, Amherst, 2004.

Tonsor, G.T., and T.C. Schroeder. "Livestock Identification: Lessons for the US Beef Industry from the Australian System." Journal of International Food \& Agribusiness Marketing 18,3/4(2006):103-18.

U.S. Department of Agriculture-Animal and Plant Health Inspection Service. National Animal Identification System (NAIS)—A User Guide and Additional Information Resources. Washington, DC, December 2007.

- A Business Plan to Advance Animal Disease Traceability. Washington, DC, September 2008a.

. 2008b. National Animal Identification System. Washington, DC. Internet site: http://animalid. aphis.usda.gov/nais/index.shtml (Accessed November 13, 2009).

2009. Premise Registration Update. Internet site: http://animalid.aphis.usda.gov/nais/ premises_id/update.shtml (Accessed November 13, 2009).

U.S. Department of Agriculture-Agricultural Marketing Service. "Mandatory Country of Origin Labeling of Beef, Pork, Lamb, Chicken, Goat Meat, Wild and Farm-Raised Fish and Shellfish, Perishable Agricultural Commodities, Peanuts, Pecans, Ginseng, and Macadamia Nuts; Final Rule." Federal Register 74,10(2009):2658707. 
lowa State University does not discriminate on the basis of race, color, age, religion, national origin, sexual orientation, gender identity, genetic information, sex, marital status, disability, or status as a U.S. veteran. Inquiries can be directed to the Director of Equal Opportunity and Compliance, 3280 Beardshear Hall, (515) 294-7612. 